\title{
A Bayesian network meta-analysis: Comparing the clinical effectiveness of local corticosteroid injections using different treatment strategies for carpal tunnel syndrome
}

\author{
Po-Cheng Chen ${ }^{1}$, Ching-Hui Chuang ${ }^{2,7^{*}}$ D, Yu-Kang Tu ${ }^{3}$, Chyi-Huey Bai ${ }^{4}$, Chieh-Feng Chen ${ }^{4,5,6}$ and Mei- Yun Liaw ${ }^{1}$
}

\begin{abstract}
Background: Local corticosteroid injections are commonly used to improve the short-term symptomatic severity and the functional status of the hands affected by carpal tunnel syndrome. We conducted a systematic review and Bayesian network-meta-analysis to compare the clinical effectiveness of local corticosteroid injections using different injection approaches.

Methods: Electronic literature in Cochrane Central Register of Controlled Trials (CENTRAL), MEDLINE, EMBASE, Web of Science, and other sources were searched to identify clinical studies comparing different injection approaches with each other or placebo for carpal tunnel syndrome. Two review authors conducted selection of studies, data extraction, and assessment of risk of bias independently. Random-effects models were used to conduct the pairwise meta-analysis and the Bayesian network meta-analysis.

Results: Overall, 10 studies with 633 patients were included in the systematic review. Among the injection approaches, local corticosteroid injections using the ultrasound-guided in-plane injection (UInar-I) approach was the best treatment strategy for clinical response (median OR versus placebo 128.30, $95 \%$ Crl 9.76 to 2299.00), change in symptom severity scale (median MD versus placebo $-1.16,95 \% \mathrm{Crl}-1.95$ to -0.38 ), and change in functional status scale (median MD versus placebo $-0.74,95 \% \mathrm{Crl}-2.00$ to 0.52 ) at short-term follow-up period in the network meta-analysis. Local corticosteroid injections using other injection approaches were better than placebo for clinical response (for the PI approach, median OR versus placebo 8.85, 95 \% Crl 3.00 to 33.15; for the $\mathrm{Dl}$ approach, median OR versus placebo $7.00,95 \% \mathrm{Crl} 0.53$ to 118.80), change in symptom severity scale (for the Ulnar-O approach, median MD versus placebo $-0.78,95 \% \mathrm{Crl}-1.43$ to -0.16 ; for the PI approach, median MD versus placebo $-0.58,95 \% \mathrm{Crl}-0.95$ to -0.22 ), and change in functional status scale (for the Ulnar-O approach, median MD versus placebo $-0.63,95 \% \mathrm{Crl}-1.67$ to 0.43 ; for the Pl approach, median MD versus placebo -0.46 , $95 \% \mathrm{Crl}-1.11$ to 0.21 ) at short-term follow-up period. The quality of studies is good.
\end{abstract}

Conclusions: According to our analyses, the ultrasound-guided in-plane injection (Ulnar-l) approach was the most effective treatment among the injection approaches for carpal tunnel syndrome.

Keywords: Network meta-analysis, Local corticosteroid injection, Carpal tunnel syndrome

\footnotetext{
* Correspondence: chinhui@cgmh.org.tw

2Department of Nursing, Kaohsiung Chang Gung Memorial Hospital, No.123,

Dapi Road, Niaosong District, Kaohsiung 83301, Taiwan

${ }^{7}$ School of Nursing, Chang Gung University of Science and Technology,

Chiayi, Taiwan

Full list of author information is available at the end of the article
}

C Biomed Central (c) 2015 Chen et al. Open Access This article is distributed under the terms of the Creative Commons Attribution 4.0 International License (http://creativecommons.org/licenses/by/4.0/), which permits unrestricted use, distribution, and reproduction in any medium, provided you give appropriate credit to the original author(s) and the source, provide a link to the Creative Commons license, and indicate if changes were made. The Creative Commons Public Domain Dedication waiver (http://creativecommons.org/publicdomain/zero/1.0/) applies to the data made available in this article, unless otherwise stated. 


\section{Background}

Carpal tunnel syndrome is a common focal peripheral neuropathy caused by compression of the median nerve at the wrist. [1] It results in pain, burning, tingling, or paresthesia in distribution of median nerve distal to the wrist $[2,3]$ The age distribution is bimodal with first peak in early 50s and second peak at age 75-84 years, and women, especially during pregnancy, are more commonly affected than men [4-6]. In United States, the prevalence of clinically diagnosed carpal tunnel syndrome among workers was $6.7 \%$, while the prevalence of confirmed carpal tunnel syndrome ranged from 2.7 to $4.9 \%$ in Sweden [7, 8].

There are many causes and risk factors for carpal tunnel syndrome, such as trauma, vascular lesions, inflammation, obesity, occupational exposure, older age, osteoarthritis, pregnancy, hypothyroidism, or autoimmune diseases [2-4, $9,10]$. The pathogenesis may be median nerve compression leading to ischemia of median nerve, which impairs neural conduction and nerve damage [4]. Carpal tunnel syndrome is a clinical diagnosis supported by specific findings on provocative tests, such as Phalen test or Tinel test [11].

The severity of carpal tunnel syndrome can be divided into 5 levels, from very mild symptoms (pins and needles sensation, pain, or sensibility loss in the fingers and/ or hand, mostly only during nighttime) to continuously very severe symptoms (pins and needles sensation, pain, significant then atrophy, and/or significant sensibility loss in the fingers and/or hand, most time) [12]. In patients with mild-to-moderate carpal tunnel syndrome, most symptoms will respond to conservative treatment or resolve spontaneously [4]. It is believed that about $34 \%$ of patients with idiopathic carpal tunnel syndrome may have spontaneous improvement [13].

Various interventions have been attempted to treat carpal tunnel syndrome. These interventions can be categorized into two types, surgical and nonsurgical interventions. The surgical interventions include open carpal tunnel release, minimal incision carpal tunnel release, or endoscopic carpal tunnel release [14-16]. The nonsurgical interventions include activity modification, wrist splints, oral medications, local corticosteroid injections, or other managements (such as laser therapy, therapeutic ultrasound, or acupuncture) $[17,18]$.

Nonsurgical interventions are usually initiated for mild to moderate carpal tunnel syndrome [19]. In most cases, local corticosteroid injection is usually considered before surgery [17]. Because the prevalence of mild to moderate carpal tunnel syndrome is high, the impact of this conservative intervention may be significant for the syndrome.

Local corticosteroid injections at the site of the carpal tunnel may reduce tendon swelling and lead to decompression of the median nerve [17]. The usual injection site is the proximal carpal tunnel near the flexor crease and just ulnar to the palmaris longus tendon. If patients have no palmaris longus tendon, ulnar to midline of wrist or just ulnar to flexor carpi radialis tendon is another choice [20-22]. The distal injection approach, in which the injection site is distal to the middle of the flexor crease, was recently used in one study [23]. Ultrasound-guided injection is gradually being adopted for accurate localization and better outcome [24, 25].

Carpal tunnel syndrome is a major disorder bothering the life quality of patients. Additionally, the syndrome interferes with the complex movements and tactile sensation of the hand [17]. Local corticosteroid injection may be the fastest and the most efficient method for improvement of symptoms. Some of the interventions have been systematically reviewed previously, and the results show that they can reduce short-term symptoms prior to definitive surgeries [26]. However, to our knowledge, no review has been conducted to assess the comparative effectiveness of different injection approaches to improve the severity and function of the hands affected by carpal tunnel syndrome. This systematic review is intended as a useful guide for patients to understand the role of different injection approaches in improving the severity and function of the hands affected by carpal tunnel syndrome.

\section{Methods}

The study included randomized placebo-controlled trials of corticosteroid injections for carpel tunnel syndrome or head to head trials evaluating different corticosteroid injections, irrespective of the dose, potency, or duration of corticosteroid, the size of syringes or needles, and angles of needle entry. Participants with mild to moderate degree of carpal tunnel syndrome were included, and there was no restriction in the mean duration of symptoms. We excluded randomized clinical trials in which participants received treatments other than local corticosteroid injections.

\section{Information sources and search strategy}

We included randomized clinical trials that assessed the effect of local corticosteroid injections using different injection approaches compared with each other or with placebo.

There were four main injection approaches for carpal tunnel syndrome.

1. Proximal corticosteroid injection (PI): The injection site is the proximal carpal tunnel near the flexor crease at the wrist.

2. Distal corticosteroid injection (DI): The injection site is distal to the middle of the flexor crease at the wrist. 
3. Ultrasound-guided in-plane injection (Ulnar-I): The needle enters the skin at the side of the transducer. The needle traverses the plane of ultrasound and the whole shaft is visualized as it progresses towards the target.

4. Ultrasound-guided out-plane injection (Ulnar-O): The needle enters the skin away from the transducer, and it is aimed at the plane of sound. With this approach, just the needle tip is visualized and the remainder of the needle is off screen.

More symptomatic relief could be reported due to more local corticosteroid injection times. To simplify the clinical conditions, we restricted the total injection times to $1 \sim 2$ times.

The study defined local corticosteroid injections using different injection approaches as different treatment strategies. The purpose of this review was to identify the overall treatment effect of a treatment strategy rather than the contribution of each component intervention towards the overall effect.

\section{Types of outcome measures}

We assessed the comparative effectiveness of available treatment strategies that aimed to improve the short-term symptomatic severity and the functional status of the hands affected by carpal tunnel syndrome. Clinical response was defined as an asymptomatic hand (VAS $<2 \mathrm{~cm}$ ), patients' satisfaction, or patients' favorable response after injection [23, 27, 28]. Boston Carpal Tunnel Questionnaire was used to evaluate the symptom severity scale (SSS, 11 items, total score $=11$ to 55 ) and the functional status scale (FSS, 8 items, total score $=8$ to 40 ). We defined change in symptom severity scale as SSS at short-term follow-up period minus SSS at baseline (SSS short-term - SSS baseline) and change in functional status scale as FSS at short-term follow-up period minus FSS at baseline (FSS short-term FSS baseline). We used the outcomes of clinical response (binary outcome), change in symptom severity scale (continuous outcome), and change in functional status scale (continuous outcome). We used outcomes assessed before or near 8 weeks.

\section{Search methods for identification of studies \\ Electronic searches}

We searched the Cochrane Central Register of Controlled Trials (CENTRAL), MEDLINE, EMBASE, and Web of Science to 31 May 2015. We also searched the World Health Organization International Clinical Trials Registry Platform search portal, which searches various trial registers, including ISRCTN and ClinicalTrials.gov (http://apps.who.int/trialsearch/Default.aspx) to identify further trials. Search strategies are available in Appendix 1. We adopted the search filters developed by the Hedges
Project (http://hiru.mcmaster.ca/hiru/HIRU_Hedges_home .aspx) to achieve best balance of sensitivity and specificity. We searched the references of the identified studies to identify additional trials for inclusion.

\section{Data collection and analysis Selection of studies}

Two review authors (P.-C. C. and C.-H. C.) independently identified the studies for inclusion by screening the titles and abstracts. We sought full text for any references that were identified for potential inclusion by at least one of the authors. We made further selection for inclusion based on the full text. We have listed the full texts of references that we excluded with reasons for the exclusion in Appendix 2. We planned to list any ongoing trials identified primarily through World Health Organization International Clinical Trials Registry Platform for further follow-up. We resolved discrepancies through discussion.

\section{Data extraction and management}

Two review authors (P.-C. C. and C.-H. C.) independently extracted the following data in Appendix 3.

1. Publication year.

2. Country in which the participants were recruited.

3. Inclusion and exclusion criteria.

4. Participant characteristics such as age, sex (male/ female), and duration of symptoms of carpal tunnel syndrome.

5. Details of the intervention and treatment strategy that aimed to relieve symptoms and improve function (e.g., contents, dose, or approaches of injections).

6. Outcomes (clinical response, change in symptoms severity scale, and change in functional status scale).

7. Risk of bias.

We sought unclear or missing information by contacting the authors of the individual trials. We resolved any differences in opinion through discussion.

\section{Assessment of risk of bias in included studies}

We followed the guidance given in the Cochrane Handbook for Systematic Reviews of Intervention to assess the risk of bias in included studies [29]. Specifically, we assessed the risk of bias in included studies for the following domains: random sequence generation (selection bias), allocation concealment (selection bias), blinding of participants and personnel (performance bias), blinding of outcome assessors (detection bias), incomplete outcome data (attrition bias), selective outcome reporting (reporting bias), and other bias (free of expertise bias) [30-36]. The risk of bias of each study was explicitly 
judged on each criterion and classified as 'low', 'high', or 'unclear'. The two review authors assessed the risk of bias of each study independently (P.-C. C. and C.-H. C.) and any disagreement was resolved through discussion to reach consensus.

\section{Measures of treatment effect}

For dichotomous variables (clinical response), we calculated the odds ratio (OR) with $95 \%$ credible interval (CrI). For continuous variables, such as change in symptom severity scale change and change in functional status scale change, we calculated the mean difference (MD) with $95 \%$ CrI.

\section{Unit of analysis issues}

The unit of analysis was the hands affected by carpal tunnel syndrome according to the intervention group to which they were randomly assigned.

\section{Dealing with missing data}

We performed an intention-to-treat analysis [30] whenever possible. Otherwise, we used data that were available to us (e.g., a trial may have reported only per-protocol analysis results). For continuous outcomes, we imputed the standard deviation from $p$ values according to guidance given in the Cochrane Handbook for Systematic Reviews of Intervention [29]. If the data were likely to be normally distributed, we used the median for metaanalysis when the mean was not available. If a study only reported the means and standard deviations for the baseline and follow-up measurements for each group, we needed to calculate the means and standard deviations for change in the outcome for these groups [31,32].

\section{Assessment of heterogeneity}

Clinical and methodological heterogeneity were assessed by carefully examining the characteristics and design of included studies. Major sources of clinical heterogeneity included age, sex, and duration of symptoms of carpal tunnel syndrome. Different study designs and risk of bias may contribute to methodological heterogeneity.

If substantial heterogeneity was identified - clinical, methodological, or statistical - we planned to explore and address heterogeneity in a subgroup analysis or meta-regression.

\section{Assessment of reporting biases}

We planned to inspect a funnel plot asymmetry to explore reporting bias [32, 33]. It was the most common tool used to assess the presence of small study effects in a meta-analysis [34]. However, because of the estimate effects for different comparisons, there was no single reference line against which symmetry could be judged. To account for the fact, 'comparison-adjusted' funnel plot was suggested [34]. If the funnel plot suggested the presence of small study effects, we explored this further by sensitivity analysis.

\section{Data synthesis}

We planned to apply classifications described in "Types of interventions" to categorize different injection approaches. We did not categorize different kinds or dose of corticosteroid into different interventions. Each category was broadly defined to encompass a relatively homogeneous group of interventions, although we anticipated that variations were noted in the way each local corticosteroid injections were applied. For example, different clinicians performed different technical skills of injections. These practice variations might be a source of heterogeneity. However, evidence was insufficient to suggest that these variations may affect the outcome. In local corticosteroid injections for carpal tunnel syndrome, a clinician typically chose one injection approach as described in "Types of interventions", which was considered as a treatment strategy, or in terms of network meta-analysis, each unique treatment strategy could be defined as a 'node'. We planned to construct a network graph based on treatment strategies used in the studies that we identified.

We planned to perform conventional pairwise metaanalyses for all outcomes and comparisons, using a random-effects model [35] by STATA (StataCorp. 2013. Stata Statistical Software: Release 13. College Station, TX: StataCorp LP.), in accordance with recommendations of The Cochrane Collaboration [29]. We then performed a network meta-analysis for the outcomes (clinical response, change in symptom severity scale, and change in functional status scale). Network metaanalysis is a method of synthesizing information from a network of trials addressing the same question but involving different interventions [36, 37]. Network metaanalysis combines direct and indirect evidence across a network of randomized trials into a single effect size, and under certain assumptions it can increase the precision in the estimates while randomization is respected [38, 39]. We performed network meta-analyses within a Bayesian framework, assuming an equal heterogeneity parameter $\tau$ across all comparisons, and we accounted for correlations induced by multi-arm studies [40]. The analysis was performed using WinBUGS (MRC Biostatistics Unit, Cambridge, UK) (http://www.mrc-bsu.cam.ac.uk/software/bugs/the-bugs-project-winbugs/), and parameters were estimated based on 100000 iterations of the Markov chains after thinning them by retaining every 100th iteration; the codes and description of the methodology can be found at http://www.bristol.ac.uk/social-community-medicine/projects/mpes/mtc/. We used a normal prior with zero mean and variance one restricted to positive 


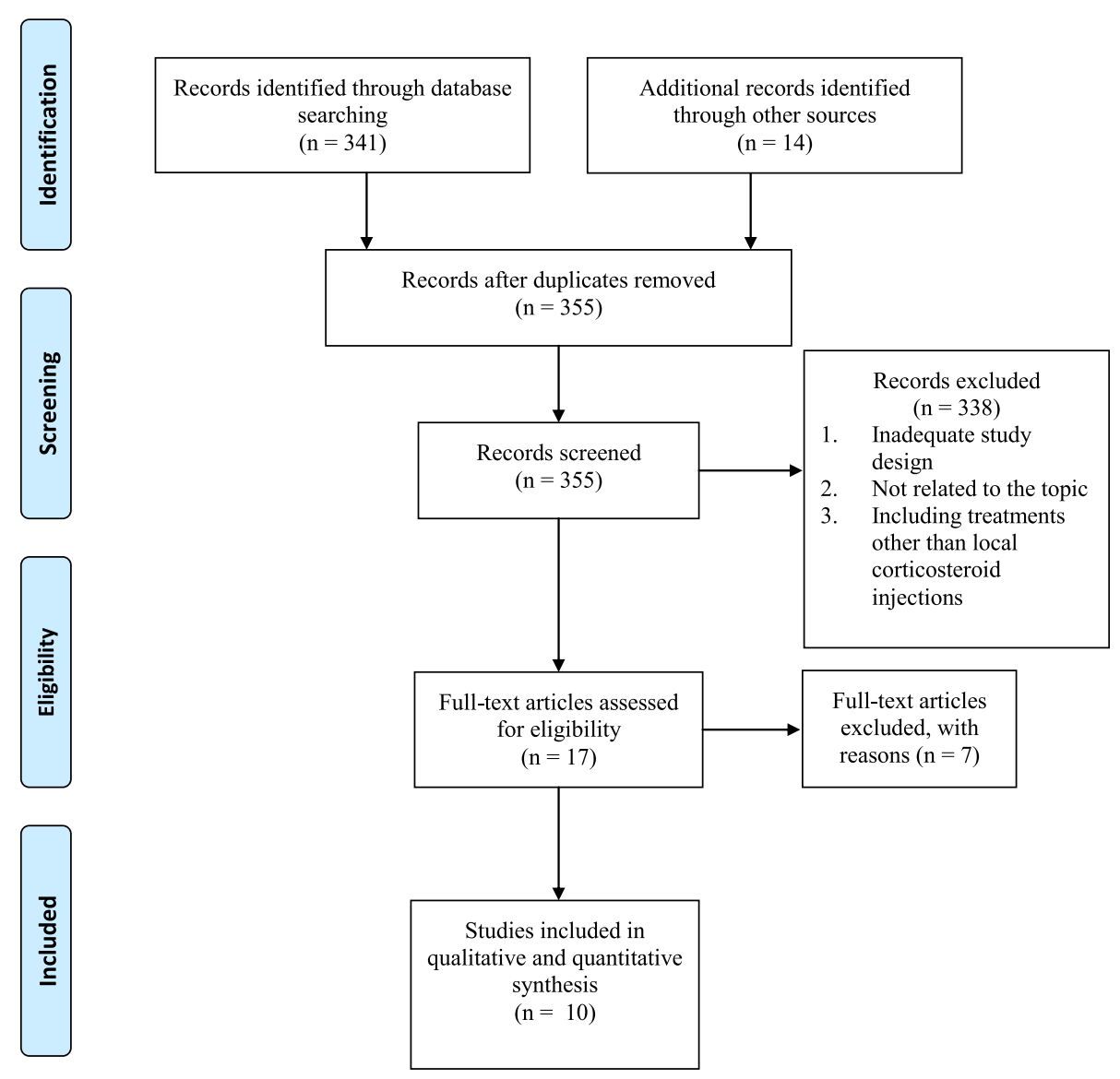

Fig. 1 Flow diagram for literature search and identifications of articles for review

values for the common heterogeneity standard deviation $\tau$ and non-informative vague priors for all mean parameters, otherwise referred as treatment effects. As a measure that reflects ranking and the uncertainty, we used the Surface Under the Cumulative Ranking curve (SUCRA) as described by Salanti et al. [41]. This measure, expressed as percentage, showed the relative probability of an intervention being among the best options.

\section{Subgroup analysis and investigation of heterogeneity}

We planned to perform the following subgroup analyses when at least one study was included in each subgroup.

1. Corticosteroid with different dose, potency, or duration.

2. Patients with different duration of symptoms.

We planned to use the $\mathrm{Chi}^{2}$ test to identify subgroup differences. We planned to consider a $p$ value $<0.05$ as statistically significant. However, we did not perform any of the above because of the few studies included in this network meta-analysis.

\section{Results}

\section{Study selection}

Figure 1 summarized the details of the study selection process and the reasons for exclusion. We identified 355 references through electronic searches and other sources. We excluded 338 inappropriate references through screening titles and reading abstracts. We retrieved 17 references for further assessment. Seven randomized controlled trials were excluded, and the reasons were described in Appendix 2 [42-48]. In total, 10 completed randomized clinical trials met the inclusion criteria $[23-25,27,28,49-53]$. We chose the outcomes (clinical response, change in symptom severity scale, and change in functional status scale) assessed at short-term (before or near 8 weeks) follow-up period from these studies.

\section{Study description}

The 10 trials included in the current systematic review were full reports published between 1999 and 2014. Table 1 summarized these studies. Because the symptom severity scale and the functional status scale in one study 
Table 1 Summary of included studies and patient characteristics

\begin{tabular}{|c|c|c|c|c|c|c|c|c|c|}
\hline Study & $\begin{array}{l}\text { Treatment strategies } \\
\text { (contents/approach) }\end{array}$ & $N$ & Age (years) & $\operatorname{Sex}(M / F)$ & $\begin{array}{l}\text { Duration of } \\
\text { symptoms (months) }\end{array}$ & $\begin{array}{l}\text { Follow-up } \\
\text { period (weeks) }\end{array}$ & $\begin{array}{l}\text { Clinical } \\
\text { response }\end{array}$ & $\begin{array}{l}\text { MD of } \\
\text { SSS (SD) }\end{array}$ & $\begin{array}{l}\text { MD of } \\
\text { FSS (SD) }\end{array}$ \\
\hline \multirow[t]{3}{*}{ Lee et al. 2014} & G1: 40 mg TCA/PI & 25 & 50.3 & $2 / 13$ & 7.6 & 4 & N/A & $-0.63(0.70)$ & $-0.02(0.75$ \\
\hline & G2: 40 mg TCAUUlnar-O & 24 & 52.6 & $0 / 14$ & 9.4 & 4 & N/A & $-0.73(0.55)$ & $-0.35(0.78$ \\
\hline & G3: 40 mg TCAVUInar-I & 26 & 55.2 & $1 / 14$ & 8.9 & 4 & N/A & $-1.16(0.62)$ & $-0.38(0.70$ \\
\hline \multirow[t]{2}{*}{ Makhlouf et al. 2014} & G1: 80 mg TCA/PI & 40 & 52.2 & $8 / 32$ & unknown & 2 & $19 / 40$ & NA & NA \\
\hline & G2: 80 mg TCA/Ulnar-I & 37 & 45.7 & $2 / 35$ & unknown & 2 & $34 / 37$ & NA & NA \\
\hline \multirow[t]{2}{*}{ Ustun et al. 2013} & G1: 40 mg MTP/PI & 23 & 42.7 & $1 / 22$ & 10.2 & 6 & N/A & $-0.95(0.63)$ & $-1.16(0.94$ \\
\hline & G2: 40 mg MTP/Ulnar-O & 23 & 46.0 & $4 / 19$ & 16.8 & 6 & N/A & $-1.27(0.61)$ & $-1.15(0.68$ \\
\hline \multirow[t]{2}{*}{ Atroshi et al. 2013} & G1: placebo & 37 & 49 & $9 / 28$ & $14 \% \leqq 12$ months & 5 & N/A & $-0.47(0.60)$ & N/A \\
\hline & G2: 40 mg MTP/PI & 37 & 44 & $10 / 27$ & $27 \% \leqq 12$ months & 5 & N/A & $-1.33(0.98)$ & N/A \\
\hline \multirow[t]{2}{*}{ Karadas et al. 2012} & G1: placebo & 30 & 48.4 & $2 / 17$ & 9.9 & 8 & N/A & $-0.03(0.52)$ & $-0.03(0.54$ \\
\hline & G2: 40 mg TCA/PI & 30 & 46.4 & $3 / 17$ & 9.5 & 8 & N/A & $-0.30(0.69)$ & $-0.15(0.92$ \\
\hline \multirow[t]{2}{*}{ Peters et al. 2010} & G1: placebo & 31 & 57.6 & $7 / 26$ & 13 & 1 & $5 / 31$ & $-0.29(0.55)$ & $0.14(0.56)$ \\
\hline & G2: 10 mg TCA/PI & 35 & 56.5 & $9 / 27$ & 26 & 1 & $17 / 35$ & $-0.92(0.71)$ & $-0.58(0.84$ \\
\hline \multirow[t]{2}{*}{ Habib et al. 2006} & G1: $35 \mathrm{mg}$ of MTP/PI & 21 & 43.3 & $4 / 17$ & 5.5 & 6 & $15 / 21$ & N/A & N/A \\
\hline & G2: $12 \mathrm{mg}$ of MTP/DI & 21 & 41 & $5 / 16$ & 6 & 6 & $14 / 21$ & N/A & N/A \\
\hline \multirow[t]{2}{*}{ Armstrong et al. 2004} & G1: 6 mg BMT/PI & 43 & 51.9 & $8 / 35$ & $61 \%>1$ year & 2 & $30 / 43$ & $-0.78(0.80)$ & $-0.64(0.87$ \\
\hline & G2: placebo & 38 & 51.2 & $10 / 28$ & $66 \%>1$ year & 2 & $13 / 38$ & $-0.19(0.62)$ & $-0.13(0.44$ \\
\hline \multirow[t]{2}{*}{ O'Gradaigh et al. 2000} & $\mathrm{G} 1: 100 \mathrm{mg} \mathrm{HC} / \mathrm{Pl}$ & 32 & unknown & unknown & unknown & 6 & $20 / 32$ & N/A & N/A \\
\hline & G2: placebo & 20 & unknown & unknown & unknown & 6 & $1 / 20$ & N/A & N/A \\
\hline \multirow[t]{2}{*}{ Dammers et al. 1999} & G1: 40 mg MTP/PI & 30 & 53 & $6 / 24$ & 32 & 4 & $23 / 30$ & N/A & N/A \\
\hline & G2: placebo & 30 & 51 & $4 / 26$ & 25 & 4 & $6 / 30$ & N/A & $\mathrm{N} / \mathrm{A}$ \\
\hline
\end{tabular}

Abbreviations:

$N$ number of treated hands; TCA triamcinolone acetonide; MTP methylprednisolone; HC hydrocortisone; BMT betamethasone; SSS symptom severity scale; FSS functional status scale; DI distal approach corticosteroid injection; PI proximal approach corticosteroid injection; UInar-I ultrasound-guided in-plane injection; UInar-O ultrasound-guided out-plane injection; $M D$ mean difference; SD standard deviation

by Lee et al. [24]. was not the average of each item as defined by other studies, we divided the mean difference and the standard deviation by 11 (11 items in symptom severity scale of Boston Carpal Tunnel Questionnaire) for the change in symptom severity scale and divided the mean difference and the standard deviation by 8 ( 8 items in functional status scale of Boston Carpal Tunnel Questionnaire) for the change in functional status scale.

There were different dose of methylprednisolone used in one trial [50], and we adopted the $40 \mathrm{mg}$ group compared to the placebo group in this meta-analysis. In addition, there were 3 different follow-up periods in the trial by Habib et al. [23], we chose the outcomes assessed at 6 weeks.

\section{Quality of studies}

Figure 2 showed the quality of the included studies. 10 studies described as randomized, 6 of which clearly described their randomize methods [25, 27, 28, 49-51]. The allocation concealment methods were described in 4 studies [28, 49-51], and the remaining did not provide details about it. 4 studies employed double blinding (patient and outcome assessor blinding) [28, 49-51]. Only 2 studies provided all of the 3 outcomes (clinical response, change in symptom severity scale, and change in functional status scale) $[28,49]$. For the part of other bias, we discussed the expertise bias, and only 2 studies did not provide the details $[28,53]$.

\section{Effects of interventions}

\section{Pairwise meta-analysis (direct comparisons)}

Figures 3, 4, and 5 provided the pooled estimates for each major outcome.

1. Clinical response Six studies with 378 participants compared each treatment strategies [23, 26-28, 51, 53]. Local corticosteroid injections using the PI approach was effective for carpal tunnel syndrome as compared to placebo (OR $=7.42,95 \%$ CI 3.53 to $15.61, \mathrm{I}^{2}=$ $29.4 \%)[28,49,51,53]$. In one study [27], local corticosteroid injections using the Ulnar-I approach showed better clinical response than by the PI approach $(\mathrm{OR}=12.53,95 \%$ CI 3.30 to 47.53$)$. 


\section{$\mathbf{a}$}

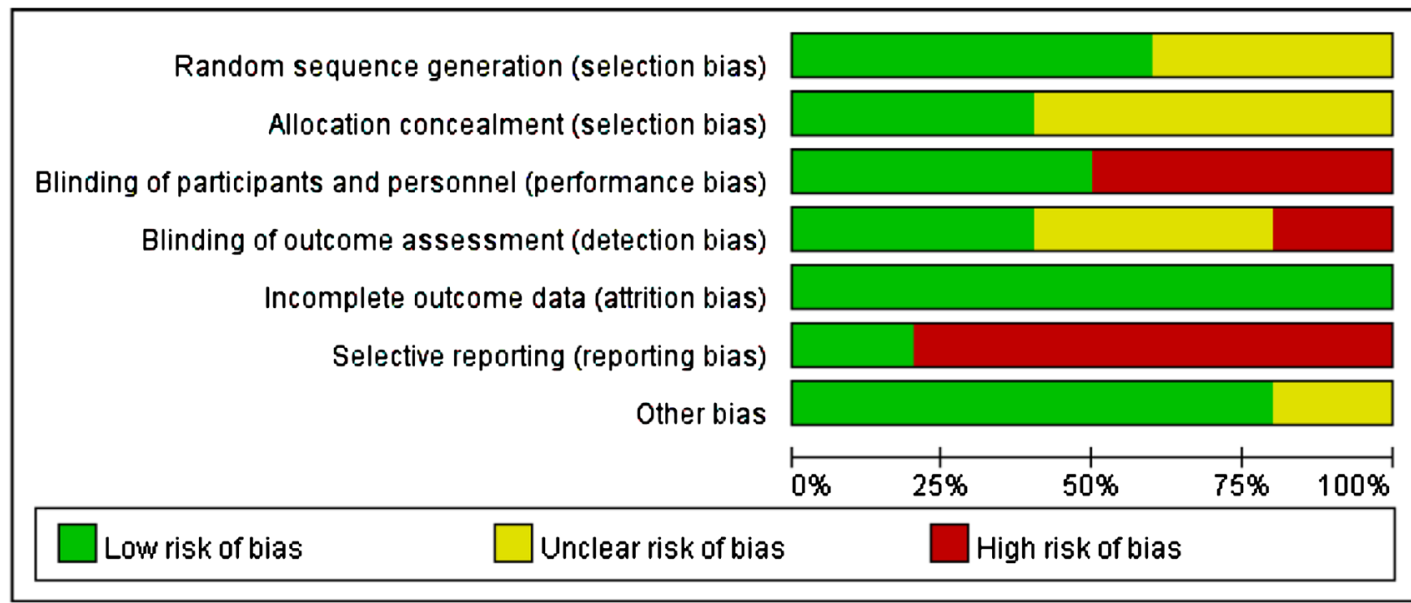

b

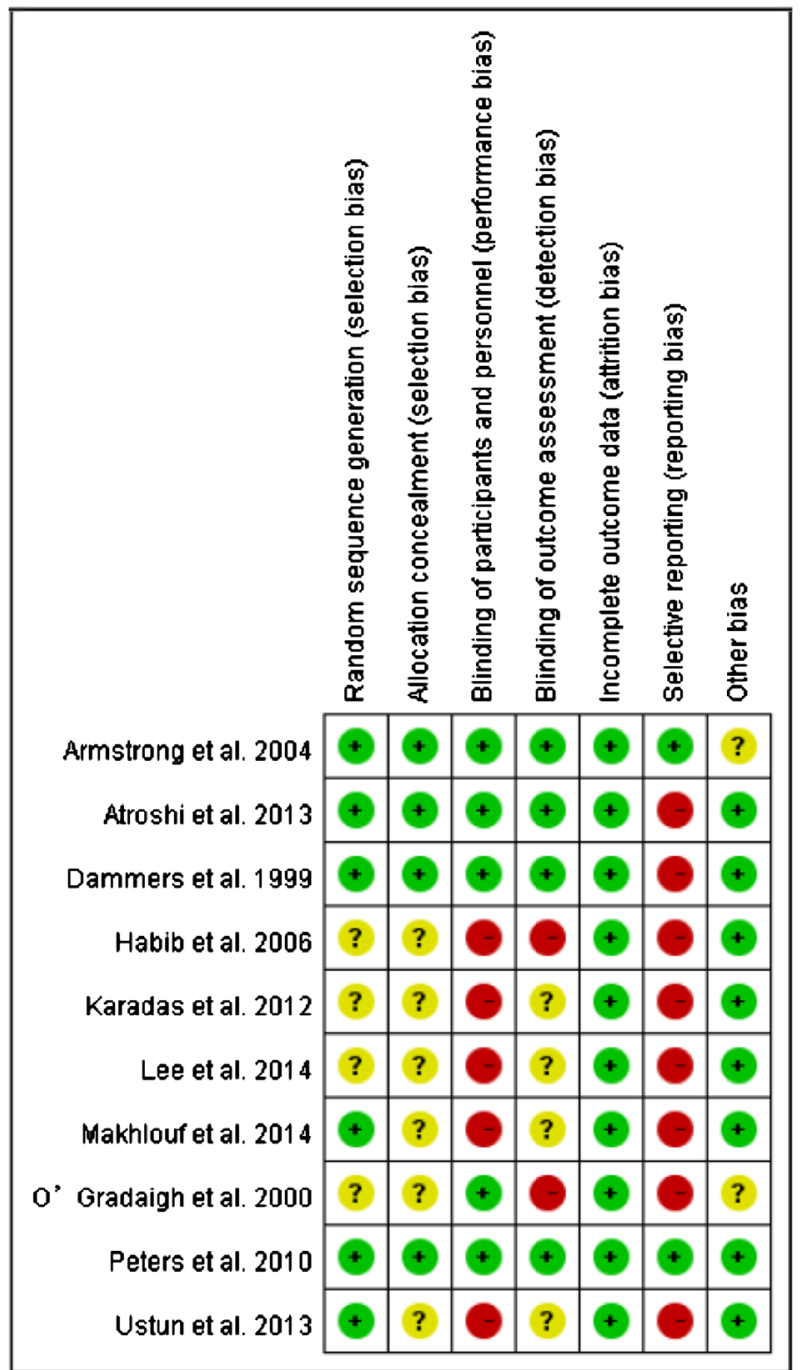

Fig. 2 Risk of bias (a) graph and (b) summary: review authors' judgements about each risk of bias item 


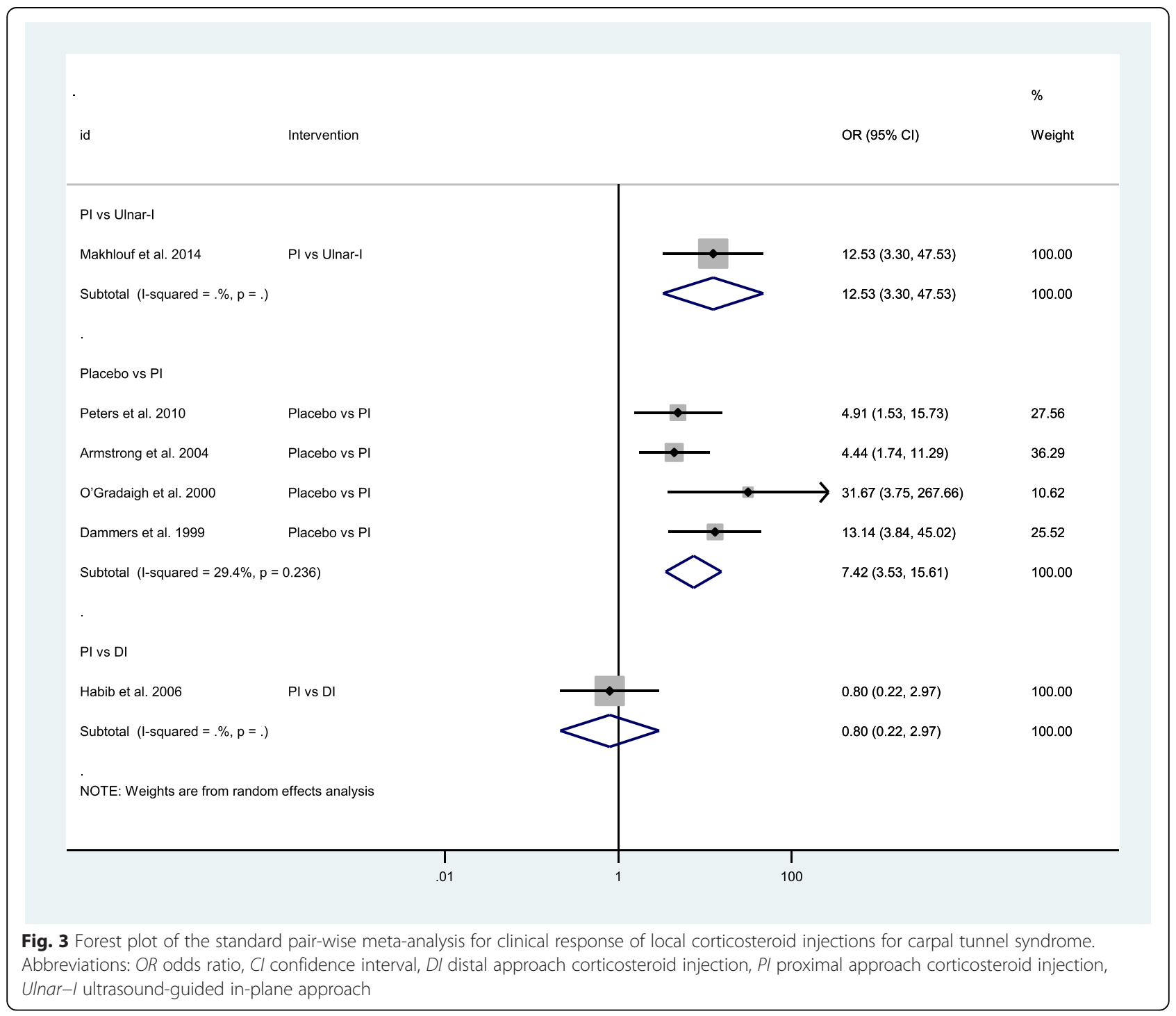

However, no statistical difference was found between the PI approach and the DI approach $(\mathrm{OR}=0.80$, $95 \%$ CI 0.22 to 2.97) [23].

2. Change in symptom severity scale Six studies with 402 participants compared each treatment strategies $[24,25,28,49,50,52]$. It appeared that local corticosteroid injections using the PI approach was effective for carpal tunnel syndrome as compared to placebo $(\mathrm{MD}=-0.58$, $95 \%$ CI -0.81 to $\left.-0.35, \mathrm{I}^{2}=51.3 \%\right)[28,49,50,52]$. In one study [24], local corticosteroid injections using the Ulnar-I approach was better than using the Ulnar-O or the PI approach respectively $(\mathrm{MD}=$ $-0.43,95 \% \mathrm{CI}-0.75$ to -0.10 ; $\mathrm{MD}=-0.52,95 \% \mathrm{CI}$ -0.89 to -0.16 ). Local corticosteroid injections using the Ulnar-O approach and using the PI approach demonstrated similar effect $(\mathrm{MD}=-0.21,95 \% \mathrm{CI}$ -0.46 to $0.04, \mathrm{I}^{2}=0.0 \%$ ) $[24,25]$.

3. Change in functional status scale

Five studies with 328 participants compared each treatment strategies [24, 25, 28, 49, 52]. Similarly, local corticosteroid injections using the PI approach was also effective for carpal tunnel syndrome as compared to placebo ( $\mathrm{MD}=-0.46,95 \% \mathrm{CI}-0.77$ to $\left.-0.14, \mathrm{I}^{2}=61.9 \%\right)[28,49,52]$. However, there was no statistical significance between the Ulnar-I and the Ulnar-O, the Ulnar-I and the PI, and the Ulnar$\mathrm{O}$ and the PI $(\mathrm{MD}=-0.03,95 \% \mathrm{CI}-0.45$ to 0.38 ; $\mathrm{MD}=-0.36,95 \% \mathrm{CI}-0.76$ to $0.04 ; \mathrm{MD}=-0.18$, $95 \% \mathrm{CI}-0.51$ to $\left.0.16, \mathrm{I}^{2}=7.8 \%\right)[24,25]$. 


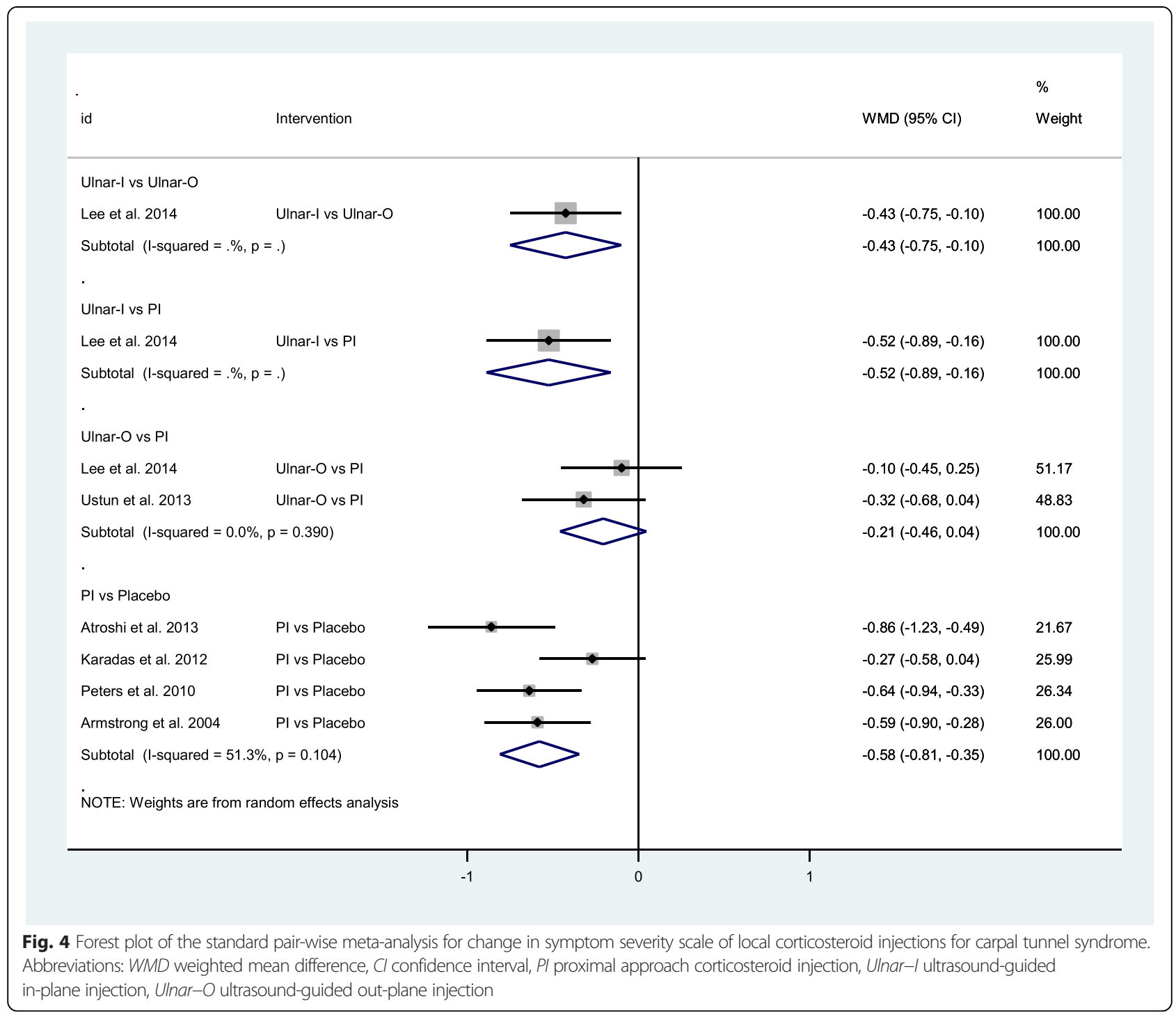

\section{Network meta-analysis (combination of direct and indirect comparisons)}

Figure 6 showed the network plots of the treatments for clinical response, change in symptom severity scale, and change in functional status scale at short-term follow-up period. Any two nodes connected by the line represented direct comparisons in the trials. The thickness of the line was proportional to the number of comparisons included in the network, and the width of the circle was proportional to the number of studies involving the specific treatment.

Table 2 reported the results of network meta-analysis, including summary posterior ORs or MDs with their $95 \%$ credible intervals of all treatment strategies and SUCRA values expressed as a percentage. Figure 7 was the rankograms to show the rank probabilities.

1. Clinical response
Six studies with 378 participants were available [23, $27,28,49,51,53]$. Local corticosteroid injections using the Ulnar-I approach might be the best choice among these interventions (median OR versus placebo 128.30, 95 \% CrI 9.76 to 2299.00; SUCRA = $98 \%$ ), followed by local corticosteroid injections using the PI approach (median OR versus placebo 8.85, 95 \% CrI 3.00 to 33.15 ; SUCRA $=54 \%$ ) and local corticosteroid injections using the DI approach (median OR versus placebo $7.00,95 \%$ CrI 0.53 to 118.80 ; SUCRA $=46 \%$ ).

2. Change in symptom severity scale

These results were provided in six studies with 402 participants [24, 25, 28, 49, 50, 52]. It appeared that local corticosteroid injections using the Ulnar-I approach was the most effective among these interventions (median MD versus placebo -1.16, $95 \%$ CrI -1.95 to -0.38 ; SUCRA $=95 \%$ ), followed by local corticosteroid injections using the Ulnar-O 


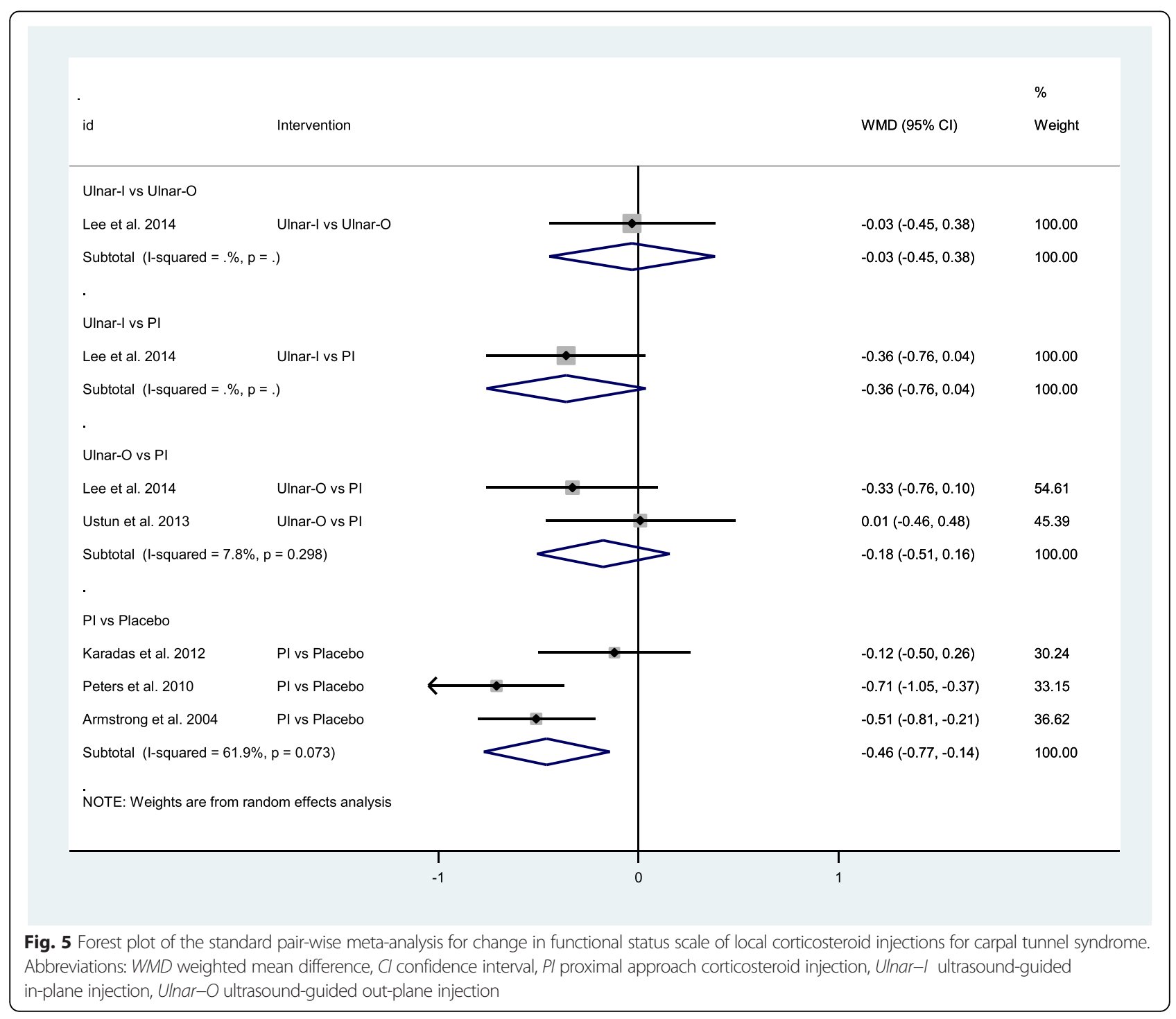

approach (median MD versus placebo $-0.78,95 \%$ CrI -1.43 to -0.16 ; SUCRA $=64 \%$ ) and local corticosteroid injections using the PI approach (median $\mathrm{MD}$ versus placebo $-0.58,95 \% \mathrm{CrI}-0.95$ to -0.22 ; SUCRA $=40 \%$ ).

3. Change in functional status scale Five studies with 328 participants provided the data $[24,25,28,49,52]$. The most effective intervention might be local corticosteroid injections using the Ulnar-I approach (median MD versus placebo -0.74 , $95 \% \mathrm{CrI}-2.00$ to 0.52 ; SUCRA $=78 \%$ ), followed by local corticosteroid injections using the Ulnar-O approach (median MD versus placebo -0.63, $95 \%$ CrI -1.67 to 0.43 ; SUCRA $=67 \%$ ) and local corticosteroid injections using the PI approach $(2 ;$ SUCRA $=48 \%)$.

\section{Subgroup analysis and meta-regression}

Subgroup analysis was not performed because of the paucity of data.

After reviewing Table 1, we came to the understanding that most cases were categorized as chronic carpal tunnel syndrome. However, we could not calculate the effect of this covariate owing to paucity of data. Likewise, various doses, potencies, and durations of corticosteroids were used for local corticosteroid injections in many studies and these also served as important covariates, but we could not calculate the effects of these covariates.

\section{Reporting bias}

The comparison-adjusted funnel plots for clinical response, change in symptom severity scale, and change in functional status scale, were shown in Fig. 8. Because 


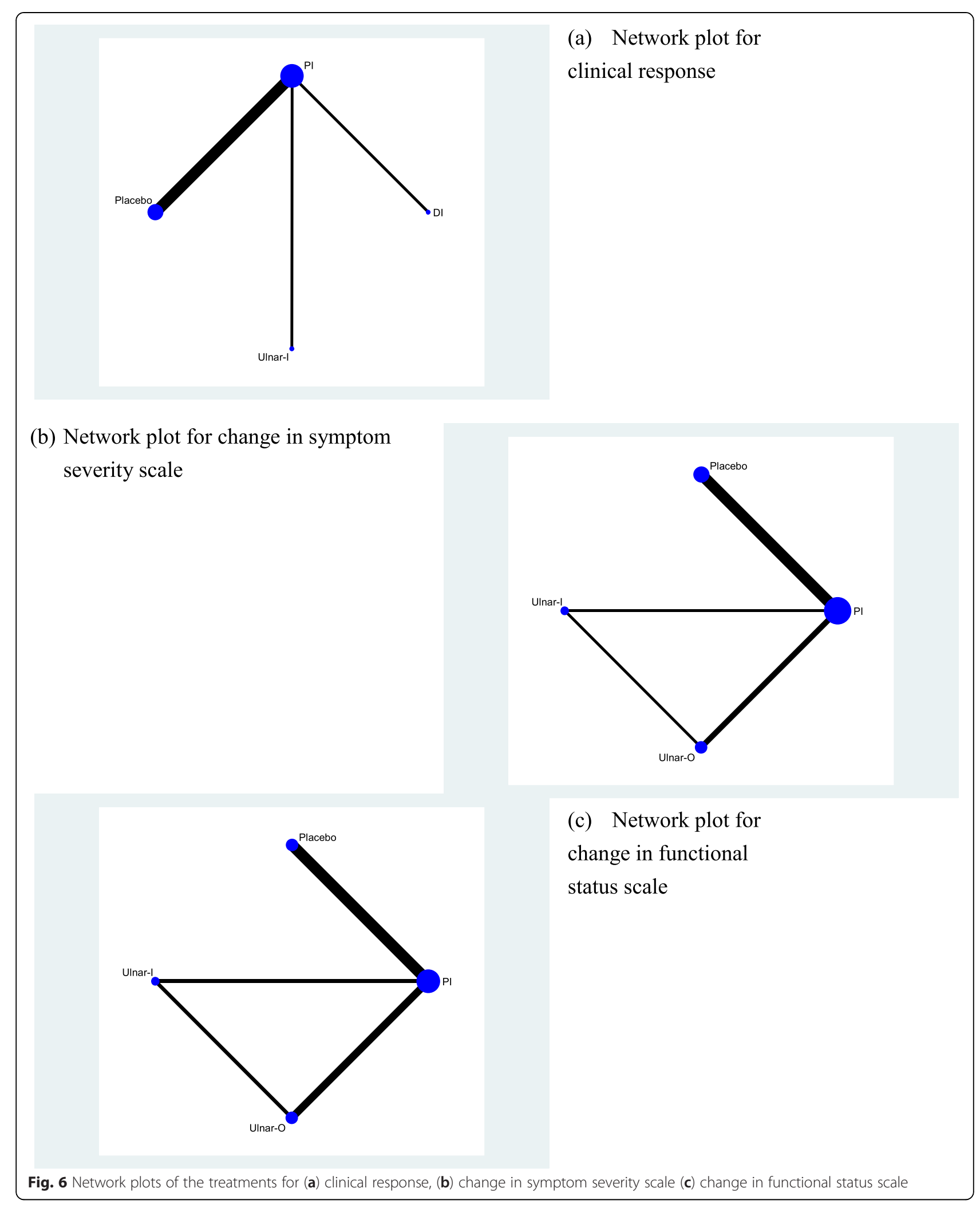


Table 2 Summary results of network meta-analysis: posterior ORs or MDs with their 95\% credible intervals of all treatment strategies and SUCRA values

\begin{tabular}{lll}
\hline & \multicolumn{3}{l}{ Clinical response versus placebo } \\
& Median OR (95\% Crl) & SUCRA \\
Ulnar-I & $128.30(9.76$ to 2299.00$)$ & $98 \%$ \\
DI & $7.00(0.53$ to 118.80$)$ & $46 \%$ \\
PI & $8.85(3.00$ to 33.15$)$ & $54 \%$ \\
& Change in symptom severity scale versus placebo \\
& Median MD (95\% Crl) & SUCRA \\
Ulnar-I & $-1.16(-1.95$ to -0.38$)$ & $95 \%$ \\
Ulnar-O & $-0.78(-1.43$ to -0.16$)$ & $64 \%$ \\
PI & $-0.58(-0.95$ to -0.22$)$ & $40 \%$ \\
& Change in functional status scale versus placebo \\
& Median MD (95\% Crl) & SUCRA \\
Ulnar-I & $-0.74(-2.00$ to 0.52$)$ & $78 \%$ \\
Ulnar-O & $-0.63(-1.67$ to 0.43$)$ & $67 \%$ \\
PI & $-0.46(-1.11$ to 0.21$)$ & $48 \%$ \\
\hline
\end{tabular}

Abbreviations:

$O R$ odds ratio; $M D$ mean difference; $\mathrm{Crl}$ credible interval; SUCRA surface under the cumulative ranking curve; $D /$ distal approach corticosteroid injection; $P I$ proximal approach corticosteroid injection; Ulnar-I ultrasound-guided in-plane injection; Ulnar-O ultrasound-guided out-plane injection

sparse spots scattered on the funnel plots, it was hard to judge if any asymmetry existed. Therefore, it was likely to present reporting bias in this network meta-analysis.

\section{Discussion}

This was the first network meta-analysis comparing local corticosteroid injections using different injection approaches for carpal tunnel syndrome. A total of 10 studies were included in the final pairwise metaanalysis and network meta-analysis. In the pairwise meta-analysis, we could know that local corticosteroid injections using the PI approach was better than placebo for clinical response, change in symptom severity scale, and change in functional status scale at shortterm follow-up period. Local corticosteroid injections using the Ulnar-I approach was more effective than local corticosteroid injections using the PI approach for clinical response, and it was also more effective than local corticosteroid injections using the Ulnar-O or the PI approach for change in symptom severity scale. There was no statistical difference among the three groups: the PI approach versus the DI approach for clinical response, the Ulnar-O approach versus the PI approach for symptom severity scale, and the Ulnar-I approach versus the Ulnar-O approach versus the PI approach for change in functional status scale. In the network-meta-analysis, the results were similar to the results of the pairwise meta-analysis, but some differences were noted. It appeared that local corticosteroid injections using the Ulnar-I approach was the most effective for clinical response, change in symptom severity scale, and change in functional status scale at short-term follow-up period.

The primary goal of local corticosteroid injections using different injection approaches was to increase the clinical response and to improve symptomatic severity or functional status of hands affected by carpal tunnel syndrome. There was no significant difference in the severity of carpal tunnel syndrome among participants receiving local corticosteroid injections because we included participants with mild to moderate degree of carpal tunnel syndrome.

Local corticosteroid injections are generally practiced as conservative treatments for carpal tunnel syndrome. Ultrasound-guided injections are also being gradually well received by many clinicians $[24,25]$. To sum up the results from the pairwise and network meta-analysis, we could deduce that:

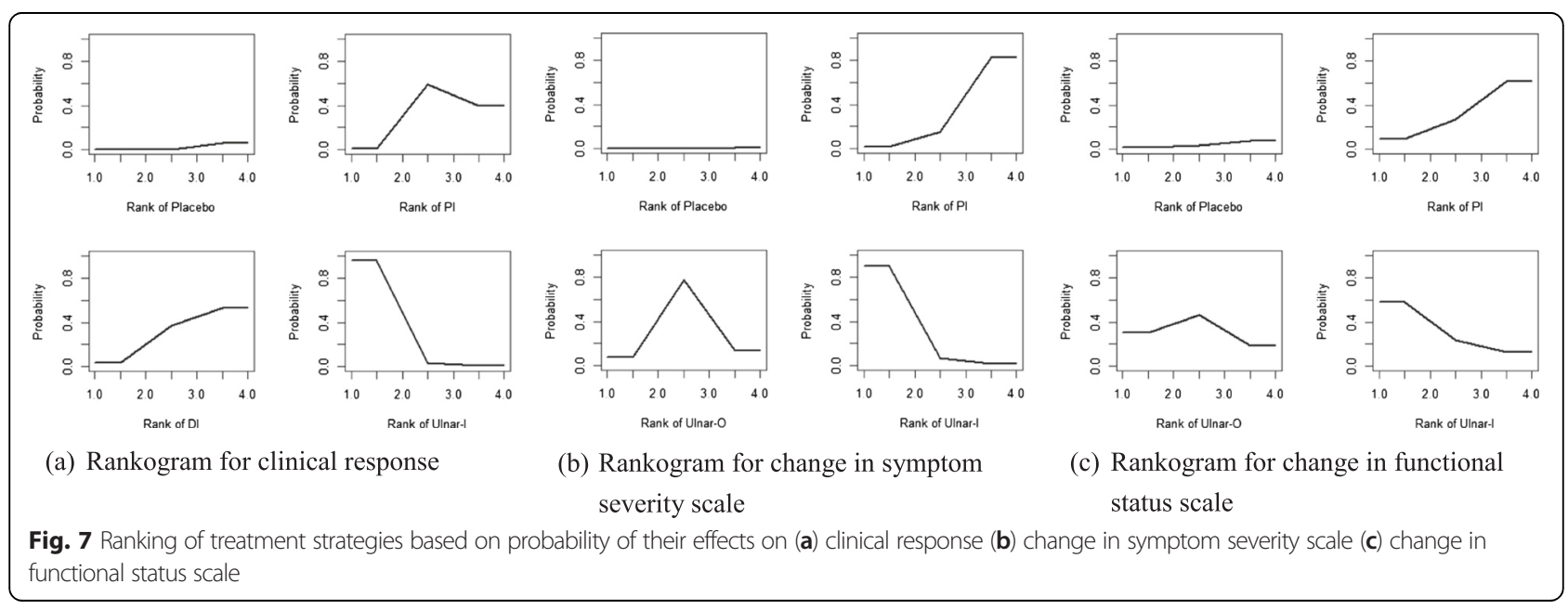




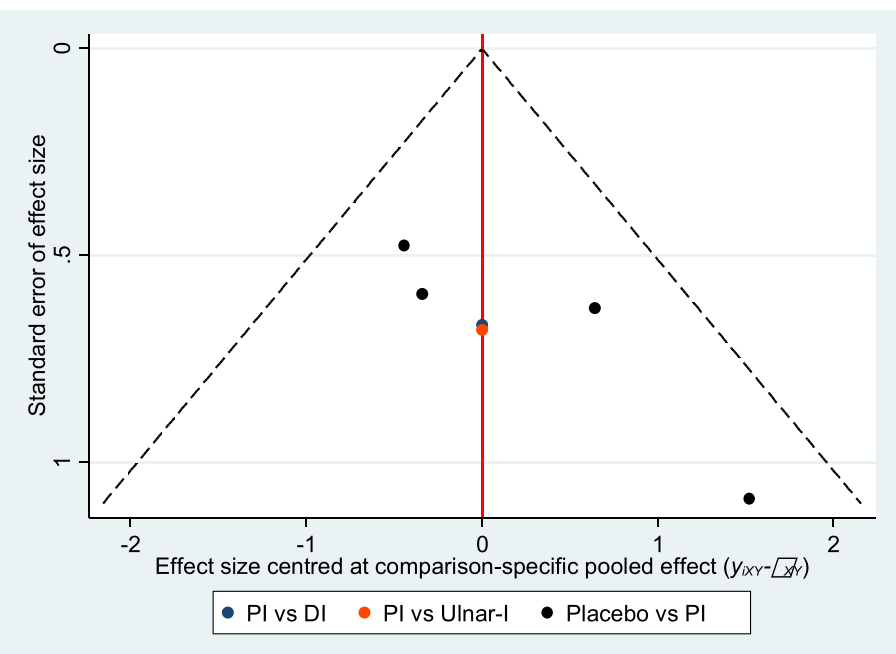

(a) Funnel plot for

clinical response

(b) Funnel plot for change in symptom severity scale
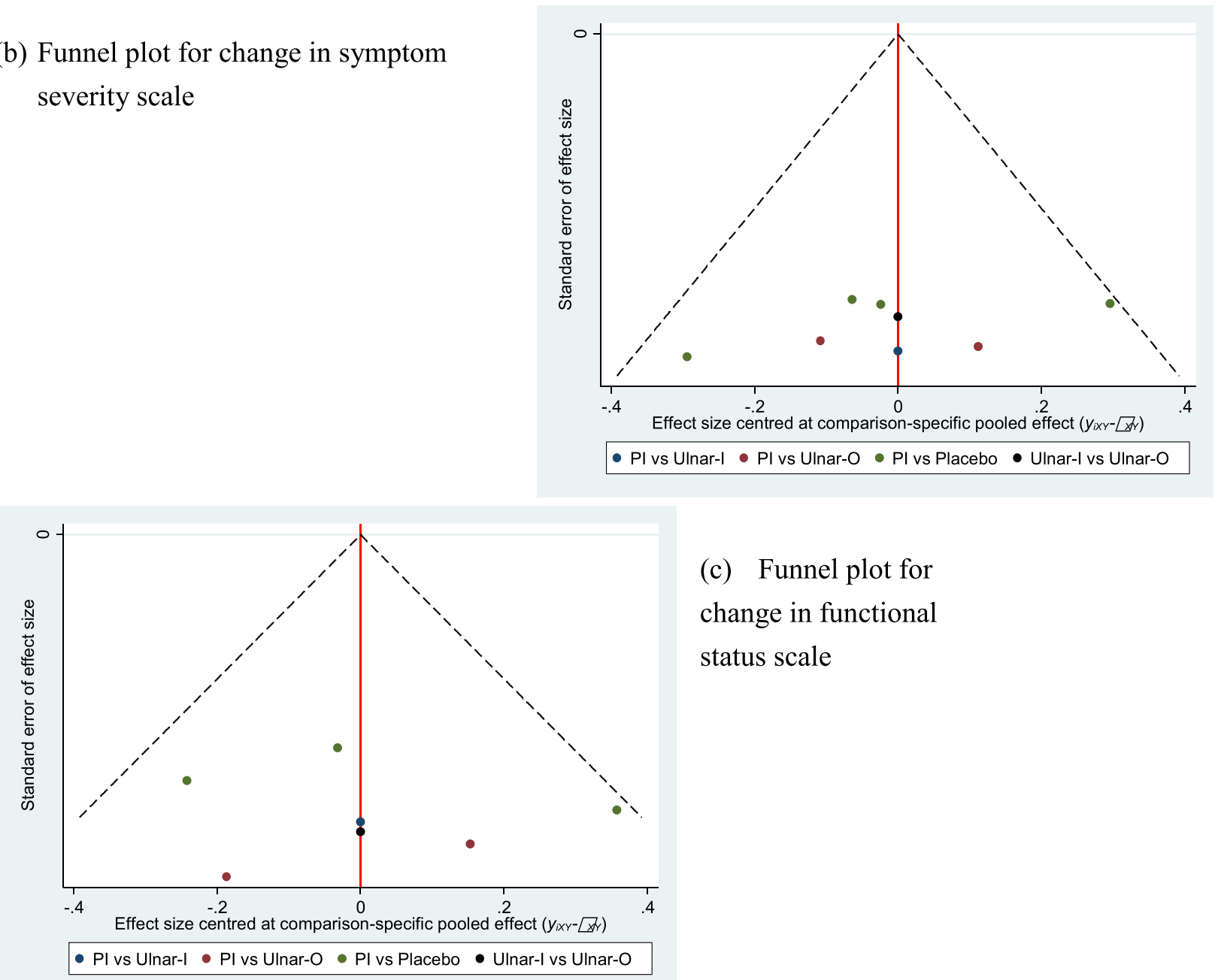

(c) Funnel plot for change in functional status scale

Fig. 8 Comparison-adjusted funnel plots for (a) clinical response (b) change in symptom severity scale (c) change in functional status scale 
1. Local corticosteroid injections were more effective than placebo for clinical response, change in symptom severity scale, and change in functional status scale at short-term follow-up period.

2. For injection approaches, the Ulnar-I approach might be more effective than the Ulnar-O approach or blind injection (including the PI and the DI approach).

Carpal tunnel syndrome was caused by increased carpal tunnel pressure, while the precise etiology was unknown. Experimental evidence suggested that anatomic compression or inflammation were possible mechanisms. [54] Through the first deduction from this meta-analysis, we favored inflammation as the major etiology of carpal tunnel syndrome for most patients. The Ulnar-I approach was recently proposed [55], and the first randomized controlled trial was completed by Lee et al. [24]. Although this injection approach seemed to be the most effective, small study effect should not be ignored. Future studies were still necessary to prove its effectiveness.

The statistical model of network meta-analysis not only provided the results of direct comparisons but also incorporated indirect comparisons that were rarely compared in the previous head-to-head studies. The strength of our study was that a practical and complete picture for the tendency of various injection approaches for the major outcomes of carpal tunnel syndrome. In addition, we also presented the probabilities of ranking for all these treatment strategies by using the Bayesian approach. The results of the probabilities of ranking could help the clinicians to choose better decisions for treatment.

Our study nonetheless had some limitations. Firstly, we did not analyze the long-term treatment effects because only few studies depicted these outcomes [44, 50, 51]. High dropout rates or referrals to surgical interventions after treatment failure were the main concerns $[56,57]$. Future efforts on the long-term effects were still required. Secondly, we did not analyze the rates for adverse events due to various severity in each clinical trials. Comparing the rates for adverse events of each treatment strategies were an essential part of patient safety in recent years. Standardization of the report for adverse events of local injections might be a good solution, and the similar concepts have been mentioned in some articles [58-60]. Thirdly, although local corticosteroid injections using the Ulnar-I approach showed the highest probability of being the best choice for clinical response, change in symptom severity scale, and change in functional status scale at short-term follow-up period, small study effect should be kept in mind and the result should be interpreted cautiously in the clinical practice. Fourthly, one study [53] reported low clinical response for the treatment arms of placebo because no injection was performed, which could bias the results by affecting the actual outcomes of the participants in the trial [61]. Therefore, this could lead to increased uncertainty in the comparisons of multiple treatments within a network meta-analysis. This could account for wide range of incredible intervals for several treatment comparisons, in which the clinical response of the treatment arms for those trials was pretty low. Finally, the effects of covariates on our meta-analysis, such as characteristics of participants, duration of symptoms, various dose, potency, or duration of corticosteroids, or methodological quality, should be considered. Nevertheless, meta-regression of subgroup analysis could not be performed in our meta-analysis due to paucity of data. Further studies in the future were necessary to clarify these influences on the treatment outcomes.

\section{Conclusion}

According to our analyses, the Ulnar-I approach was the most effective treatment for clinical response, change in symptom severity scale, and change in functional status scale among the injection approaches for carpal tunnel syndrome.

\section{Abbreviations}

PI: Proximal corticosteroid injection; DI: Distal corticosteroid injection; UlnarO: Ultrasound-guided out-plane injection; Ulnar-I: Ultrasound-guided in-plane injection; Crl: Credible interval; SUCRA: Surface under the cumulative Ranking curve.

\section{Competing interests}

The authors declare that they have no competing interests.

\section{Authors' contributions}

All authors approved the final manuscript. Y-KT had full access to all of the data in the study and took responsibility for the integrity of the data and the accuracy of the data analysis.

Study concept and design: P-CC, Y-KT, C-HB, C-HC.

Acquisition, analysis, or interpretation of data: P-CC, C-HC, C-HB

Drafting of the manuscript: P-CC, C-HC

Critical revision of the manuscript for important intellectual content: C-HC, Y-KT, C-HB, C-FC

Statistical analysis: P-CC, C-HC, Y-KT.

Administrative, technical, or material support: C-FC.

Study supervision: Y-KT, C-HB.

\section{Acknowledgment}

We thank Chiu-Ping Leong and Ya-Ping Pong for the coordination of the study and reviewing the manuscript.

\section{Author details}

'Department of Rehabilitation, Kaohsiung Chang Gung Memorial Hospital, Kaohsiung, Taiwan. 'Department of Nursing, Kaohsiung Chang Gung Memorial Hospital, No.123, Dapi Road, Niaosong District, Kaohsiung 83301, Taiwan. ${ }^{3}$ Institute of Epidemiology and Preventive Medicine, College of Public Health, National Taiwan University, Taipei, Taiwan. ${ }^{4}$ School of Public Health, Taipei Medical University, Taipei, Taiwan. ${ }^{5}$ Division of Plastic Surgery, Department of Surgery, Wan Fang Hospital, Taipei Medical University, Taipei, Taiwan. ${ }^{6}$ Cochrane Taiwan, Taipei Medical University, Taipei, Taiwan. ${ }^{7}$ School of Nursing, Chang Gung University of Science and Technology, Chiayi, Taiwan.

Received: 29 July 2015 Accepted: 12 November 2015

Published online: 19 November 2015 


\section{References}

1. Sternbach G. The carpal tunnel syndrome. J Emerg Med. 1999;17(3):519-23.

2. Katz JN, Simmons BP. Clinical practice. Carpal tunnel syndrome. N Engl J Med. 2002;346(23):1807-12

3. Viera AJ. Management of carpal tunnel syndrome. Am Fam Physician. 2003; 68(2):265-72.

4. Aroori S, Spence RA. Carpal tunnel syndrome. Ulster Med J. 2008;77(1):6-17

5. Bland JD, Rudolfer SM. Clinical surveillance of carpal tunnel syndrome in two areas of the United Kingdom, 1991-2001. J Neurol Neurosurg Psychiatry. 2003;74(12):1674-9.

6. Tanaka S, Wild DK, Seligman PJ, Behrens V, Cameron L, Putz-Anderson V. The US prevalence of self-reported carpal tunnel syndrome: 1988 National Health Interview Survey data. Am J Public Health. 1994;84(11):1846-8.

7. Atroshi I, Gummesson C, Johnsson R, Ornstein E, Ranstam J, Rosen I. Prevalence of carpal tunnel syndrome in a general population. JAMA. 1999;282(2):153-8.

8. Luckhaupt SE, Dahlhamer JM, Ward BW, Sweeney MH, Sestito JP, Calvert GM. Prevalence and work-relatedness of carpal tunnel syndrome in the working population, United States, 2010 National Health Interview Survey. Am J Ind Med. 2013;56(6):615-24.

9. Harris-Adamson C, Eisen EA, Dale AM, Evanoff B, Hegmann KT, Thiese MS, et al. Personal and workplace psychosocial risk factors for carpal tunnel syndrome: a pooled study cohort. Occup Environ Med. 2013;70(8):529-37.

10. Palmer KT, Harris EC, Coggon D. Carpal tunnel syndrome and its relation to occupation: a systematic literature review. Occup Med (Lond). 2007;57(1):57-66

11. MacDermid JC, Wessel J. Clinical diagnosis of carpal tunnel syndrome: a systematic review. J Hand Ther. 2004;17(2):309-19.

12. Verhagen $A P$, de Vet $H C$, de Bie RA, Kessels AG, Boers M, Bouter $L M$, et al. The Delphi list: a criteria list for quality assessment of randomized clinical trials for conducting systematic reviews developed by Delphi consensus. J Clin Epidemiol. 1998;51(12):1235-41.

13. Padua L, Padua R, Aprile I, Pasqualetti $P$, Tonali P. Multiperspective follow-up of untreated carpal tunnel syndrome: a multicenter study. Neurology. 2001;56(11):1459-66.

14. Agee JM, McCarroll Jr HR, Tortosa RD, Berry DA, Szabo RM, Peimer CA. Endoscopic release of the carpal tunnel: a randomized prospective multicenter study. J Hand Surg Am. 1992;17(6):987-95.

15. Ariyan S, Watson HK. The palmar approach for the visualization and release of the carpal tunnel. An analysis of 429 cases. Plast Reconstr Surg. 1977 ; 60(4):539-47.

16. Klein RD, Kotsis SV, Chung KC. Open carpal tunnel release using a 1-centimeter incision: technique and outcomes for 104 patients. Plast Reconstr Surg. 2003;111(5):1616-22

17. Huisstede BM, Friden J, Coert JH, Hoogvliet P, European HG. Carpal tunnel syndrome: hand surgeons, hand therapists, and physical medicine and rehabilitation physicians agree on a multidisciplinary treatment guideline-results from the European HANDGUIDE Study. Arch Phys Med Rehabil. 2014;95(12):2253-63.

18. Sim H, Shin BC, Lee MS, Jung A, Lee H, Ernst E. Acupuncture for carpal tunnel syndrome: a systematic review of randomized controlled trials. J Pain. 2011;12(3):307-14.

19. Duncan KH, Lewis Jr RC, Foreman KA, Nordyke MD. Treatment of carpal tunnel syndrome by members of the American Society for Surgery of the Hand: results of a questionnaire. J Hand Surg Am. 1987;12(3):384-91.

20. Tallia AF, Cardone DA. Diagnostic and therapeutic injection of the wrist and hand region. Am Fam Physician. 2003;67(4):745-50.

21. Hutten-Czapski P. The occasional carpal tunnel injection. Can J Rural Med. 2007;12(3):176-7.

22. Rifat SF, Moeller JL. Site-specific techniques of joint injection. Useful additions to your treatment repertoire. Postgrad Med. 2001;109(3):123-126, 129-130, 135-126.

23. Habib GS, Badarny S, Rawashdeh H. A novel approach of local corticosteroid injection for the treatment of carpal tunnel syndrome. Clin Rheumatol. 2006;25(3):338-40.

24. Lee JY, Park Y, Park KD, Lee JK, Lim OK. Effectiveness of ultrasoundguided carpal tunnel injection using in-plane ulnar approach: a prospective, randomized, single-blinded study. Medicine (Baltimore). 2014;93(29), e350.

25. Ustun N, Tok F, Yagz AE, Kizil N, Korkmaz I, Karazincir S, et al. Ultrasoundguided vs. blind steroid injections in carpal tunnel syndrome: A single- blind randomized prospective study. Am J Phys Med Rehabil. 2013:92(11):999-1004.

26. Marshall Shawn C, Tardif G, Ashworth Nigel L. Local corticosteroid injection for carpal tunnel syndrome. In: Cochrane Database of Systematic Reviews. Hoboken: Wiley; 2007.

27. Makhlouf T, Emil NS, Sibbitt Jr WL, Fields RA, Bankhurst AD. Outcomes and cost-effectiveness of carpal tunnel injections using sonographic needle guidance. Clin Rheumatol. 2014;33(6):849-58.

28. Peters-Veluthamaningal C, Winters JC, Groenier KH, Meyboom-de Jong B. Randomised controlled trial of local corticosteroid injections for carpal tunnel syndrome in general practice. BMC Fam Pract. 2010;11:54.

29. Higgins JPT, Green S (editors). Cochrane Handbook for Systematic Reviews of Interventions Version 5.1.0 [updated March 2011]. The Cochrane Collaboration, 2011. Available from www.cochrane-handbook.org.

30. Newell DJ. Intention-to-treat analysis: implications for quantitative and qualitative research. Int J Epidemiol. 1992;21(5):837-41.

31. Tu YK, Baelum V, Gilthorpe MS. The problem of analysing the relationship between change and initial value in oral health research. Eur J Oral Sci. 2005;113(4):271-8

32. Egger M, Davey Smith G, Schneider M, Minder C. Bias in meta-analysis detected by a simple, graphical test. BMJ. 1997:315(7109):629-34.

33. Begg CB. A comparison of methods to detect publication bias in metaanalysis by P. Macaskill, S. D. Walter and L. Irwig, Statistics in Medicine, 2001; 20:641-654. Stat Med. 2002;21(12):1803. author reply 1804.

34. Chaimani A, Higgins JPT, Mavridis D, Spyridonos P, Salanti G. Graphical tools for network meta-analysis in STATA. PLoS One. 2013;8(10), e76654

35. DerSimonian R, Laird N. Meta-analysis in clinical trials. Control Clin Trials. 1986;7(3):177-88

36. Mills EJ, loannidis JP, Thorlund K, Schunemann HJ, Puhan MA, Guyatt GH. How to use an article reporting a multiple treatment comparison metaanalysis. JAMA. 2012;308(12):1246-53.

37. Cipriani A, Higgins JPT, Geddes JR, Salanti G. Conceptual and technical challenges in network meta-analysis. Ann Intern Med. 2013;159(2):130-7.

38. Lu G, Ades AE. Combination of direct and indirect evidence in mixed treatment comparisons. Stat Med. 2004;23(20):3105-24.

39. Glenny AM, Altman DG, Song F, Sakarovitch C, Deeks JJ, D'Amico R, et al. Indirect comparisons of competing interventions. Health Technol Assess. 2005;9(26):1-134. iii-iv.

40. Salanti G, Marinho V, Higgins JPT. A case study of multiple-treatments metaanalysis demonstrates that covariates should be considered. J Clin Epidemiol. 2009;62(8):857-64.

41. Salanti G, Ades AE, loannidis JP. Graphical methods and numerical summaries for presenting results from multiple-treatment meta-analysis: an overview and tutorial. J Clin Epidemiol. 2011;64(2):163-71.

42. Akarsu S, Karadas O, Tok F, Levent Gul H, Eroglu E. Single versus repetitive injection of lignocaine in the management of carpal tunnel syndrome-a randomized controlled trial. J Hand Surg Eur Vol. 2015; 40(2):179-83.

43. Breuer B, Sperber K, Wallenstein S, Kiprovski K, Calapa A, Snow B, et al. Clinically significant placebo analgesic response in a pilot trial of botulinum $B$ in patients with hand pain and carpal tunnel syndrome. Pain Med. 2006;7(1):16-24.

44. Dammers JW, Roos Y, Veering MM, Vermeulen M. Injection with methylprednisolone in patients with the carpal tunnel syndrome: randomised double blind trial testing three different doses. J Neurol. 2006;253(5):574-7.

45. Girlanda P, Dattola R, Venuto C, Mangiapane R, Nicolosi C, Messina C. Local steroid treatment in idiopathic carpal tunnel syndrome: short- and longterm efficacy. J Neurol. 1993;240(3):187-90.

46. Kamanli A, Bezgincan M, Kaya A. Comparison of local steroid injection into carpal tunnel via proximal and distal approach in patients with carpal tunnel syndrome. Bratisl Lek Listy. 2011;112(6):337-41.

47. Karadas O, Tok F, Ulas UH, Odabasi Z. The effectiveness of triamcinolone acetonide vs. procaine hydrochloride injection in the management of carpal tunnel syndrome: a double-blind randomized clinical trial. Am J Phys Med Rehabil. 2011;90(4):287-92.

48. Wong SM, Hui AC, Lo SK, Chiu JH, Poon WF, Wong L. Single vs. two steroid injections for carpal tunnel syndrome: a randomised clinical trial. Int J Clin Pract. 2005;59(12):1417-21.

49. Armstrong $T$, Devor W, Borschel L, Contreras R. Intracarpal steroid injection is safe and effective for short-term management of carpal tunnel syndrome. Muscle Nerve. 2004;29(1):82-8. 
50. Atroshi I, Flondell M, Hofer M, Ranstam J. Methylprednisolone injections for the carpal tunnel syndrome: a randomized, placebo-controlled trial. Ann Intern Med. 2013;159(5):309-17.

51. Dammers JW, Veering MM, Vermeulen M. Injection with methylprednisolone proximal to the carpal tunnel: randomised double blind trial. BMJ. 1999;319(7214):884-6.

52. Karadas O, Tok F, Akarsu S, Tekin L, Balaban B. Triamcinolone acetonide vs procaine hydrochloride injection in the management of carpal tunnel syndrome: randomized placebo-controlled study. J Rehabil Med. 2012:44(7):601-4

53. O'Gradaigh D, Merry P. Corticosteroid injection for the treatment of carpal tunnel syndrome. Ann Rheum Dis. 2000;59(11):918-9.

54. Amirfeyz R, Gozzard C, Leslie IJ. Hand elevation test for assessment of carpal tunnel syndrome. J Hand Surg Br. 2005;30(4):361-4.

55. Kim DH, Jang JE, Park BK. Anatomical basis of ulnar approach in carpa tunnel injection. Pain Physician. 2013;16(3):E191-198.

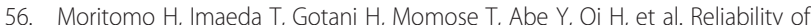
the Hand20 questionnaire: comparison with the 36-Item Short-Form Health Survey. Hand Surg. 2014;19(1):1-6.

57. Hayward AC, Bradley MJ, Burke FD. Primary care referral protocol for carpal tunnel syndrome. Postgrad Med J. 2002;78(917):149-52.

58. Kohl KS, Bonhoeffer J, Braun MM, Chen RT, Duclos P, Heijbel H, et al. The Brighton Collaboration: Creating a Global Standard for Case Definitions (and Guidelines) for Adverse Events Following Immunization Advances in Patient Safety: From Research to Implementation (Volume 2: Concepts and Methodology). Rockville MD: Agency for Healthcare Research and Quality (US); 2005.

59. Bian ZX, Tian HY, Gao L, Shang HC, Wu TX, Li YP, et al. Improving reporting of adverse events and adverse drug reactions following injections of Chinese materia medica. J Evid Based Med. 2010;3(1):5-10.

60. Coplan P, Chiacchierini L, Nikas A, Shea J, Baumritter A, Beutner K, et al. Development and evaluation of a standardized questionnaire for identifying adverse events in vaccine clinical trials. Pharmacoepidemiol Drug Saf. 2000;9(6):457-71.

61. Higgins JPT, Altman DG: Chapter 8: Assessing risk of bias in included studies. In: Higgins JPT, Green S (editors). Cochrane Handbook for Systematic Reviews of Interventions Version 5.0.0 [updated February 2008]. The Cochrane Collaboration, 2008. Available from www.cochrane-handbook. org. 2008.

\section{Submit your next manuscript to BioMed Central and take full advantage of:}

- Convenient online submission

- Thorough peer review

- No space constraints or color figure charges

- Immediate publication on acceptance

- Inclusion in PubMed, CAS, Scopus and Google Scholar

- Research which is freely available for redistribution 